\title{
7. Access to essential environmental technologies and poor communities: why human rights should be prioritized
}

\section{Oche Onazi*}

\subsection{INTRODUCTION}

Everything is contaminated, land, water, plants, and people.

Community member Ecuador. ${ }^{1}$

Climate change is commonly understood as a global phenomenon, but it is equally, even though it is rarely acknowledged, a particular phenomenon. It is particular phenomenon for some of the poorest communities in the world, given that their ability to respond to climate change is impeded by a combination of institutional, social, economic and geographical factors. Many lives in Africa, Asia and Latin America (for purposes here, the Third World $)^{2}$ are either already condemned or potentially condemned by the effects of climate crisis. Floods and droughts, which have in turn contributed to massive hunger, amongst other problems, in many parts of the Third World, constitute the most visible signs of climate change. ${ }^{3}$

The future for poor communities in the Third World is bleak if the implications of the available statistics on climate change from the United Nations Framework Convention on Climate Change (UNFCCC) are anything to go by. The UNFCCC predicts that a 20 to 30 per cent rise in greenhouse gas (GHG) emissions by 2030 will lead to a 3 per cent rise in temperature this century, and this will further lead to a number of anticipated consequences, including an increase in disease, reduction of crop yields and rise in hunger. ${ }^{4}$ Climate change, the UNFCCC says, would further exacerbate Third World food security by contributing to the destruction of 20 to 30 per cent of all plant and animal species. The 
existing levels and sources of water supply, however dismal they already may be, are also put at risk by climate change. In Africa, for instance, as much as an estimated 250 million people will predictably lose their water supply. This will in turn further affect food production, basic healthcare and the overall quality of their lives. Adaption to climate change also presents a range of challenges, from the difficulty of accessing finance, to the lack of meaningful community action, to weak human and institutional capacity for research into appropriate adaptation strategies. ${ }^{5}$ Another challenge is that the success of climate change measures depends on the ability to integrate both the mitigation and adaptation strategies into the existing social and economic policies on poverty alleviation, healthcare and development, amongst other policies.

As much as they are closely related concepts, vulnerability and adaptation, however, require different initiatives to respond to climate change, including (but not always) the role of information and a range of technologies. And just as there is a need to understand the different ways in which individuals and communities are vulnerable or ill-adaptable to climate change, there is also the need to understand the diversity of responses to climate change. The advantage of focusing on diversity is that this would be an attempt to understand the different sources of vulnerability between community and community, country and country, rich and poor, including the specific responses needed to adapt and mitigate climate change. Differentiation entails the protection of the needs of the vulnerable, which can easily be overlooked in the process of developing partnerships and cooperative activities, as some chapters of this book seek to promote, regarding access to environmental technologies. While it is true that we are all fellow sufferers of climate change, it must also be appreciated, as argued in this chapter, that we suffer differently. We need different solutions to respond to climate change-related suffering.

The importance of differentiation can further be justified from the perspective of environmental technologies, even though they lack an agreed definition. ${ }^{6}$ Environmental technologies can simply be defined according to their relevance to climate change. Furthermore, environmental technologies are often distinguished as between those that are relevant to mitigation, on the one hand, and those relevant to adaptation to climate change, on the other. ${ }^{7}$ What this implies is that the relevance of environmental technologies would often vary as this would always be determined by the extent to which a particular range of technologies are relevant to either adaptation or mitigation. The value and relevance of a type of environmental technology is also further determined by the atmospheric conditions of the particular community involved. For 
example, new plant varieties and climate tolerant crops might be more important to agrarian communities than they would be to communities whose sources of livelihood are not agrarian-related. Communities in desert affected areas prone to water scarcity, and those in tropical communities vulnerable to water-borne diseases, would need specific technologies relevant to their problems. Of course, there are technologies that would be relevant to all communities, such as renewable energy technologies. Even so, this would also depend on the type of technology, as different renewable technologies would have to be matched against different sources of energy.

Following on from the above, two related arguments are presented in this chapter regarding access to environmental technologies, with particular reference to poor and remote communities in the Third World. The first is that access to environmental technologies should benefit from differentiated approaches, which would prioritize the needs of the poor. As a follow-up to this argument, human rights should, as suggested by Tuncak in this collection, serve as a means through which access to environmental technologies can be prioritized on behalf of such communities. By their orientation, human rights imply an ethos that can ably represent all kinds of vulnerability, including that which occurs from the lack of access to environmental technologies. What follows is a discussion of the main problem which this chapter seeks to address, that is, the failure to prioritize the needs of the poor and vulnerable regarding access to environmental technologies. Part of the problem related to this, also discussed, is the narrow definition of access, which is restricted to the innovative process. This is followed by a discussion of the importance of differentiation, and how it can lead to prioritization, and furthermore, how human rights can be used to support this objective.

\subsection{DOES HISTORY TEACH US ANYTHING?}

What experience and history teach is this - that people and governments never have learned anything from history, or acted on principles deduced from it. $^{8}$

Hegel's words in the epigraph are quite compelling about our inability to learn from the past. This may be for different reasons, including the contested nature of historical narratives themselves. One reading of this, though, is that history often consists of stories of winners and losers, and the stories of losers are often the ones that get left out, with no bearing on future conduct, especially on public policy-related conduct. This 
might explain why it is so easy to repeat policies that have been proved to be harmful to millions in the past. History, in this sense, or a particular version of history, often finds it easy to repeat itself. This is what calls for scepticism, not so much about the inability to learn from history, but rather about the inability to learn the right lessons from history. In the context of this chapter, it calls for scepticism concerning the ongoing international discussions about access to environmental technologies, mainly as a result of the historic role IPRs have played in aggravating the conditions of the poor in the Third World. There is a danger that the dark history of IPRs, as told by the losers, stands a chance of being overlooked in favour of a more celebratory account of its history, one that is told by the winners in this context. It is this account of history that must be resisted if the interests of the poor regarding access to environmental technologies are to be prioritized. The two possible historical narratives that might influence the ongoing discussions regarding environmental technologies are presented below.

\subsection{AGAINST IPRS}

No one helps anymore, the hungry lives for himself and the satiated lives for himself.

Zawyet Sultan, Egypt. ${ }^{9}$

We get sick and we don't have the money to get cured. We don't have medicines because they are expensive ... Everything is expensive.

Women, Juncal, Ecuador. ${ }^{10}$

The account of those denied medicines or food for different reasons, including the role of IPRs, are unlikely to favour any proposals for IPRs in relation to environmental technologies. ${ }^{11}$ It might be speculative, but they might even question why any consideration is being given to IPRs regarding environmental technologies, especially after their experiences of encountering the parochialism of agri-business and pharmaceutical companies. In spite of what might seem obvious to the poor, the failure to grasp the full dimension of the dark history of IPRs could lead to their needs, aspirations, lives and sources of livelihood currently threatened by climate change to be silenced, as they were in relation to access to medicines, water and food. Suddenly, from the tone of some of the debates, the urgency of climate change is no longer so pressing. A familiar tone of language is now being used: leave it to the (intellectual property and international trade) market, the market knows best, it is the 
only way that we can equitably distribute the technologies necessary to address climate change.

Many in the Third World have heard and experienced the misery, pain and hardship of the market. Instead of medicine, water or food, for instance, it was, and has been, disease, hunger and death. The history of IPRs has been a history of exclusion, and also, the failure to prioritize the needs of the poor. It is not at all surprising that the Third World country delegations at various UNFCCC meetings have expressed a great deal of scepticism over proposals attempting to bring environmental technologies within the remit of the Trade-Related Aspects of Intellectual Property Rights (TRIPS) and World Trade Organization (WTO) agenda of neoliberalism. ${ }^{12}$ They are sceptical about whether IPRs would lead to the kind of cooperation anticipated by the UNFCCC towards climate change mitigation and adaptation.

Patents, in particular, have been used to abuse rather than encourage access to various public goods under the WTO's TRIPS remit. Strategies of exclusion, refusal and restriction have been used to silence the needs of the poor. While the public health declaration is often celebrated in ways that show that there are opportunities within TRIPS that make the agreement amenable to the needs of the poor, the most important lesson is that IPRs maintained the interests of pharmaceutical firms. It is a lesson of the resilience of narrow trade-related interests. The real lesson to be learnt from those series of events is the failure to prioritize the interests of the poor, and the ingenuity of trade or market interests of corporations in asserting and reasserting their claims.

What is consistent within this debate are the attempts by corporations to reassert their interests, including the use of human rights claims to disguise such narrow interests. ${ }^{13}$ It should not be forgotten that the public health declarations in South Africa were contested (although it was later dropped under public pressure) by litigation instigated by 39 powerful pharmaceutical firms. ${ }^{14}$ Besides, the fact that human rights concerns are proposed as an exception to the rule rather than the rule itself further validates this argument. After all, the declarations on national emergencies or compulsory licences only suspend the exclusive right of the innovator temporarily. ${ }^{15}$ Ironically, the suspension of human rights, whether of healthcare, food or water, under the TRIPS remit is permanent. Individuals and communities are only entitled to access affordable medicines temporarily. 


\subsection{IPRS ARE ALL WE NEED}

The history and narrative of IPRs has not always been described as it was above. There is a different account, one of celebration of the vast potential and scope within the mandate of the WTO's TRIPS regimes. It is this version of history that can threaten the environmental technology rights of the poor. On this account, TRIPS is not malevolent, but rather a benevolent institution, one that can bend to accommodate the needs of the poor. As the saying goes, TRIPS offers some 'flexibilities' that can be used to benefit the poor, particularly by limiting the power of the IP owner insofar as certain conditions are met. TRIPS has often been regarded as an embodiment of rights and obligations, which balances various demands, leading to restrictions on the power of the IPR holder. As discussed by Srinivas in this collection, the TRIPS Agreement, ${ }^{16}$ particularly in Article 7, provides the mandate to balance between rights and obligations, and Article 8 further provides that public interests in relation to socio-economic issues must also be taken into account. Article 7 has become a reference point for those who argue that TRIPS is, after all, not so disadvantageous, but actually the most pragmatic and appropriate way of enabling access to environmental technologies. Here is an example of this kind of optimism.

Given the tension between IP protection and the transfer of technology a 'balancing act' is necessary to ensure international IP rules advance broader public policy objectives. Such balance is considered to be particularly important in the context of the TRIPS Agreement, which establishes the most comprehensive standards of IP protection, both in terms of areas covered and their applicability to all members of the WTO. ${ }^{17}$

On this view, TRIPS is essential to climate change initiatives, even though this would depend on getting the balance right. Sadly, this kind of optimism, even amongst the most fervent critics of the IP regime, does not give priority to the interest of the poor. What the poor require instead are approaches that single out and deal specifically with their needs. What they require is for their interests to be treated incommensurably as opposed to being treated commensurably with corporate interests. A good way of clarifying this point is by drawing an analogy between this particular issue and the philosophical and constitutional debates about the balancing of rights against other societal interests. ${ }^{18}$ Many participants in this debate regard incommensurability as a secure way of safeguarding and achieving rights. ${ }^{19}$ Quite apart from that, commensurability is really concerned with the consequences of certain actions. An action is only 
pursued if it would lead to certain desired outcomes. Apart from the question of 'favourable to whom?', the problem is that the intrinsic value of the action itself is taken for granted. Commensurability, a utilitarian argument, refers to the choices open to agents amongst valuable competing alternatives. ${ }^{20}$ The most valuable alternatives in this regard are those that can be measured according to their effects on utility. On this calculation, the imposition of harms can be justified on the basis that such types of action maximize utility. ${ }^{21}$

This is an uncertain position to hold in relation to the question of access, since this ultimately fails to prioritize the interests of the poor. There are no guarantees from a utilitarian calculation. ${ }^{22}$ It is a similar suggestion that is being made here about access of the poor to environmental technologies. Incommensurability is strategic for the protection of such minority interests, whether they are rights or something else. One should be sceptical about balancing, for it is simply an attempt to make incommensurable values or interests commensurable. The problem is that commensurability implies compromise, of the kind that can threaten the lives of the poor.

\subsection{THE DEFINITIONAL PROBLEM}

Before discussing one of the ways the needs of the poor can be prioritized, I pause for a moment to discuss another important factor that also contributes to the lack of priority. This relates to the prevailing understanding of what access entails. In the existing literature access simply refers to 'technology transfer' or the transfer of processes relating to innovation. It refers to processes relating to those who 'use and evolve technology in their own institutions and businesses' ${ }^{23}$ This problem is not addressed even by definitions of access that emerge from Third World perspectives. They do not extend the perception of access beyond the innovative process. According to these perspectives, access is defined as the transfer of skills and knowledge to 'enable local people, farmers, firms and governments design and make technologies'. ${ }^{24}$ It refers to the transfer of the full technological cycle, particularly research and development. ${ }^{25}$ While this may have a significant advantage, however, it does not go far enough in expanding the current perception of access. Its advantage is that it helps us understand that 'innovation' is not just a question of developing new inventions or ground-breaking technology, but also about sharing the technology and information that currently exists. As helpful as this definition is, its disadvantage is that it does not consider 
access beyond those involved in the actual technological process, particularly those who use technology for their daily lives.

A further problem with this narrow definition of access is that it misses out on some of the important nuances and wider issues that could serve as an impediment in relation to the question of technologies. In particular, apart from the general inequalities between technology-advanced countries and technology-disadvantaged states, the existing definition of access, and the debates that follow on from it, do not capture the unequal nature of technological development between and within countries. For instance, the definition fails to account for the unequal nature of technological development within the Third World itself that makes debates about IPRs irrelevant to most countries. While Brazil, China, India or South Africa can potentially benefit from the current system, the same cannot be said about Chad, Niger, Malawi and Gabon, amongst other countries. The definition does not account for communities in failed states like Zimbabwe, Côte D'Ivoire, Congo or Somalia, or those in states like Nigeria, where there is a different degree of state failure. ${ }^{26}$ In all these cases, the definition does not account for poor and remote communities, who are potential end-users of technology. In light of this, only a definition that is able to lead to initiatives that directly engage with various communities within these respective countries is desirable and will prioritize the interests of the poor. This is a call to understand the need for approaches that move beyond state-based or market-based initiatives to those that target communities specifically. ${ }^{27}$

The point being made is that the perception of access itself needs to be broadened beyond those who make the technology, to include those who actually use technologies for their daily activities and sources of livelihood. After all, we are not all innovators or inventors of technologies; we are mostly users of technologies. Ironically, the TRIPS Agreement provides the closest recognition of the users of technology. It does so in Article 7 cited above, when it suggests that technologies should be disseminated in a way that benefits the mutual advantage of both 'producers and users of technological knowledge and in a manner conducive to social and economic welfare' ${ }^{28}$ As wide as this seems, however, it does not go far enough, for it operates within the narrow boundaries of the WTO TRIPS system. Furthermore, it is unclear who qualify as users in this context. For instance, are they individuals, communities or corporate entities? As such, a much broader understanding of access is still needed, particularly as regards environmental technologies. 


\subsection{RECOGNITION OF DIFFERENCE}

It is important to understand that technologies are required generally as much as they are required specifically. Local action for climate change is as necessary as global action. The persistency of broken promises from the realpolitick of the global climate change debates only reinforces the case for prioritizing the needs of the poor by encouraging different kinds of community action. ${ }^{29}$ At the risk of stating this point simplistically, and also at the risk of a lack of specificity, the argument is nonetheless that existing ecological challenges in different parts of the world today cannot effectively be tackled without prioritizing and empowering the respective communities to take some form of control or action. ${ }^{30}$ At a level of abstraction, the concept of recognition is one way of bringing this and other issues to attention. The idea of recognition has received a lot of philosophical treatment in relation to different societal problems, from race, ethnicity, gender and sexuality, amongst other things. Recognition refers to an interpretation of the different struggles against material equality, such that are ill-accounted for in mainstream theories of justice. It is likened to a claim for the recognition of one's humanity on the basis of its uniqueness, specificity and difference within a political community. Recognition implies an ethical relationship created by the process of the identification of the uniqueness of other individuals. Recognition has an intrinsic element to it, which constitutes, socializes, universalizes and reconciles individuals with others, their communities and the world as a whole. ${ }^{31}$ What is most important about recognition, however, is the attention it draws to plurality. It draws attention to the difference between individuals and communities. It must also be mentioned that recognition has a radical side. This comes from the specificity it helps assert, which is expressed against others, sometimes with the effect of creating adversaries.

Given its radical potential, it is not surprising that recognition is beginning to feature in relation to problems of the environment, even though not many have applied it directly to environmental technologies. One advocate of recognition in relation to the environment more generally is Schlosberg. ${ }^{32} \mathrm{He}$ specifically builds on the work of protagonists of this viewpoint, such as Young ${ }^{33}$ and Fraser, ${ }^{34}$ to warn against blindly applying liberal theories of justice to environmental problems. His concern is that advocates of environmental justice - like the theories of justice they follow - have emphasized distribution at the expense of recognition. Like Fraser, in particular, Schlosberg argues that demands for (environmental) justice ought to be understood as both demands for 
redistribution and recognition, even though he pays more attention to the latter than the former in this context. He does this by picking up on Fraser's work, which connects the two strands of thought together, that is, redistribution and recognition. The emphasis on recognition, all the same, comes out more prominently in her work, as she points to the limit of constructing ideal schemes and procedures for justice without, first of all, examining the inequality that permeates in society, which in turn prevents people from participating equally. Attempts to remedy inequality would only have substance if they recognize the relationship between recognition and redistribution.

Strongly persuaded by that argument, I would argue in relation to environmental technologies that recognition of the specificity is a condition precedent to distribution. Recognition is prior to, or the first step towards, redistribution. This is simply because the redistribution of resources can only be readily available if all those who are currently excluded are recognized. It would be misleading, in the light of arguments in this chapter on behalf of the poor, to think that access to technologies is first of all or only a question of redistribution. This would overlook the poor's different conditions or abilities and misleadingly assume that they are able to access the processes or mechanisms relevant to the distribution of technological resources in the same way as more opulent communities. Claims for recognition bring such issues to our attention and prioritize the kind of responses needed for the excluded.

This is perhaps Schlosberg's point about the limitations of environmental justice theories. The problem is that they take John Rawls' theory of justice unquestionably, and pay too much attention to fair procedures under the 'veil of ignorance', under which goods and services should be distributed. Fair distribution is the cornerstone of Rawls' theory, as it has become central to environmental justice theories. Following on the work of Young, Schlosberg argues that what they have missed are the 'social, cultural, symbolic and institutional conditions', ${ }^{35}$ which are integral to redistribution, and which would always affect the fairness of distribution.

What is being suggested is that inadequate distribution is not the only reason for injustice. The lack of recognition of difference is also constitutive of injustice. Social difference is a fact of life, whether it is achieved through privilege or oppression. ${ }^{36}$ What is required by justice is the understanding of such differences, particularly how they contribute to the injustice of distribution. This is what the concept of recognition brings to attention, just as it emphasizes the importance of participation. Recognition is, after all, a political stance to participate in the decisionmaking process. It responds to the question of who actually participates, 
a question not sufficiently addressed under the veil of ignorance, especially because of its false assumption of equality.

\subsection{HUMAN RIGHTS}

Human rights provide an important mechanism through which claims for recognition, differentiation and participation can be articulated. This is because human rights are, according to Costas Douzinas, what 'establish the recognition necessary for the constitution of a full personality'. ${ }^{37}$ Douzinas pursues this argument by relying on the work of Alex Honneth, ${ }^{38}$ who is not only a strong proponent of recognition, but also one who has particularly gone to some lengths to show the ethical relationship implied in struggles for recognition. They provide an important mechanism that can be used to channel one's identity and uniqueness as a human being.

Law and rights, together with love and solidarity, are pivotal to achieving recognition. Unlike love and solidarity, however, legal recognition has a more central role to play. Legal recognition is achieved through rights, particularly when rights holders assert their claims against duty bearers. Rights create a process of mutual recognition by establishing legal subjects with duties towards each other, thereby creating a generalized system of norms. The advantage of this is that individuals learn to respect one another through the reciprocity demanded from the relationship between rights holders and duty bearers.

Without being exhaustive, legal recognition has the following advantages. First, it draws attention to the intrinsic value of all individuals since legal recognition is premised on a notion of universal morality. It allows individuals to rise above instrumental relationships and treat each other intrinsically. Secondly, the effect of recognition is the legal autonomy it creates, which leads to the moral autonomy and responsibility it bequeaths rights holders. This is another way of describing what human dignity entails. Legal recognition leads to self-respect. It is the consequence of the realization of human rationality, moral action and the intrinsic value of individuals. As Douzinas says, it helps individuals appreciate that, 'I too am capable of moral action and that, like others, I am an end in myself.' ${ }^{39}$ Rights are realized from respecting the rights of others. As such, human dignity is about the recognizable capacity to assert claims. As a legal subject, rights become the symbol of equality. What is important to take from Douzinas' arguments about rights is how it assists law to create an ethical state, which is the result of a two-stage 
transition. Law moves from the abstract to the moral and then, finally, to the ethical state.

Building on the insights above, two related questions come to mind. The first is what is it about the nature of human rights that make them significant to recognition, and secondly, what (if any at all) is the necessary connection between human rights and environmental technologies? These issues are discussed in turn. The strength of human rights comes from their raison d'être, even though this still divides opinions amongst philosophers and legal theorists today. Apart from the question of what human rights are, the question of what human rights are for is not only unclear but contestable. Responses to this question are likely to give rise to different answers, which are difficult to present concisely or comprehensively in this context, except to indicate one possible way of understanding their significance. The point of human rights cannot sufficiently be grasped without coming to terms with what ways they can assist, make visible and respond to the alleviation of human suffering. ${ }^{40}$ This is primarily what makes recognition possible, as it depends on what we first of all identify as human suffering. The point is that without the ability to recognize, the ability to respond will not arise. Here, again, the mutual relationship between human rights and recognition is reiterated.

The advantage of placing emphasis on human suffering is the focus it draws towards exclusion and vulnerability, something which can be explained from the recent and encouraging influence of human rightstype arguments on climate change debates. ${ }^{41}$ It is more generally through such arguments that the relationship between environmental technologies and human rights can specifically be understood. It is the human suffering provoked by climate change that has given rise to human rights arguments. Human rights arguments are gaining weight in this context, mostly because of the fact that climate change potentially affects specific human rights, such as life, health, food, water, shelter and property, as well as others that bear on human livelihood. ${ }^{42}$

The advantage of human rights then, as Mary Robinson ${ }^{43}$ similarly argues, is that they draw attention to human suffering or "the human misery that results directly from the damage we are doing to nature' ${ }^{44}$ It is a damage, she says, that is already negatively impacting on many communities that have little or no remedies accessible to them. This is certainly something that implies access to technologies and, as argued here, the language of human rights in bringing this to our attention. Access to knowledge, information and technology would easily form part of the responses to climate change, once they are linked up with debates 
about the depletion of the earth's natural resources and the enjoyment of various human rights.

What human rights can contribute to the agenda is the moral and social content also necessary to achieve the objective of universal and equitable access to environmental technologies. Importantly, a human rights orientation can help pay attention to different human situations of vulnerable communities. It can assist in appreciating that such vulnerable communities not only lack the resources to acquire technologies, but also the information and other means necessary to mitigate and adapt to climate change. Human rights can provide the necessary standard of vigilance, which in turn would constantly direct and redirect the focus of related approaches to voiceless or invisible communities. Looked at this way, human rights can assist, recognize and prioritize interests in favour of the urgent and differentiated technology needs of communities already living in anxious circumstances.

The second point regarding the specific relationship between human rights and environmental technologies is more difficult to make, even though this link has already been made through the discussions above about the broader relationship between human rights and the environment. There is, however, a further way that the relationship between human rights and environmental technologies can be established. This can be achieved by proposing human rights procedurally as opposed to creating a substantive right to environmental technologies. It is easier to understand human rights in the context of debates about access to technologies as procedural rights that guarantee the fairness of procedures for all processes, including the processes leading up to the distribution of environmental technologies. This possibility rests on the normative content of human rights - non-discrimination, equality, empowerment and participation, amongst other things - which can be used to enable access to poor and remote communities by constraining, drawing attention, including or positively discriminating on their behalf.

This argument also allows us to understand human rights as ethical guides, which like other rival ethics, direct moral or legal action. We can think of human rights as a whole, as a framework that directs right actions. After all, in the many ways human rights have been understood, they have been understood as ethical rights, which is different from and precedes their positive law understandings. ${ }^{45}$ Human rights, to borrow from Sen's words, are also 'ethical imperatives' ${ }^{46}$ that tell us what to do. Parallels here can be drawn with the use of human rights in development discourse. The rights-based approaches to development are dominated by procedural and ethical uses of human rights, which emphasize values 
such as participation, equality, non-discrimination and freedom of expression in relation to the processes of design and evaluation of public law and policy for development. ${ }^{47}$ The use of human rights in relation to environmental technologies can be developed in a similar way, as this would ground all questions of access on basic human rights-based notions of justice and equality. Looked at this way, human rights would therefore serve as a sort of moral audit or benchmark for the objectives of enabling wide levels of access to environmental technologies, particularly amongst the poor. After all, questions of equitable access have important ethical implications, which make foundational values imperative to approaches regarding access to environmental technologies.

\subsection{CONCLUSION}

These aspects of human rights discussed above make them a useful and necessary tool for the more general approaches regarding climate change in general, and access to environmental technologies, in particular. Human rights are important because of their strength and capability of speaking on behalf of the interests of poor communities. What this means is that, if there should come such a time that approaches lose sight of the objective of encouraging access, human rights can also serve as an ethos that redirects action. One can think of human rights, in this sense, as instruments that would constantly disturb the status quo if, or when, the related approaches deviate from their intended objectives. Human rights would provide us with the ethical lens to encourage vigilance and also to question the extent to which attention is being paid to the right issues or if the right questions are being asked.

A question that remains unresolved, however, is one that takes us back to some of the issues this chapter began with; that is, is it plausible or otherwise to place environmental technologies within the remit of the WTO agenda? This chapter has been against this, since it is unlikely that issues concerning the poor would be prioritized within this body. This is the main reason for the argument in this chapter that poor and remote communities are more likely to benefit from differentiated approaches than collapsing their interests with corporate interest within the WTO agenda. There are different practical examples which provide ideas on how to prioritize the needs of the poor, ranging from the creation of cooperative enterprises to specially designed social businesses, as Nobel Laureate Mohammed Yunus' work referred to earlier has shown. To recall, these are non-profit making businesses, which function under different market rules, and are designed to solve particular problems. 
Davies' contribution to this collection (see Chapter 4) is also important to understanding the opportunities that might be available in this respect.

A further reason why the WTO is unlikely to prioritize the needs of the poor comes from the central role devised for human rights in this chapter. There is always a danger that the values protected by human rights are likely to be abused if they are placed within the WTO agenda. ${ }^{48}$ It is important to remain steadfast in resisting the corporate capture of human rights by continuing to show, as $\operatorname{Garcia}^{49}$ has done, the underlying normative conflict between both agendas. There are different values and indeed theories of justice that underpin each approach, which offer different objectives, and which may indeed contradict not support one another. Fundamentally, they are influenced by different sources of moral reasoning which cannot be reconciled; for example, IPRs are consequentialist and utilitarian in nature. Comparatively speaking, human rights are influenced by a different kind of moral reasoning, which in simple terms is deontological.

\section{NOTES}

* A slightly different version of this chapter was presented at the British Academy Expert Meeting, 'Obtaining, protecting and using environmental technologies: a holistic analysis', 13 April 2011. I thank Dr Abbe Brown and all other participants at the expert meeting for comments and discussions on certain aspects of this chapter. I also wish to thank Profs Andrea Ross and Colin Reid, both of the School of Law, University of Dundee, for their comments on an early draft of this chapter.

1. World Bank, Dying for Change: Poor People's Experience of Health and Ill-Health (World Bank, 2005) 13.

2. The use of the term 'Third World' has certainly been controversial for several reasons, most of which cannot adequately be treated in this context. The purpose of the use of the term Third World here is to signal the aspirations of peoples or groups of countries unlikely to benefit from the IPR regime. On the use of the term Third World, see B. Rajagopal, 'Locating the Third World in cultural geography' in Third World Legal Studies (1988) 20.

3. See Oxfam International, 'Adapting to climate change: what's needed in poor countries, and who should pay', Briefing Paper (Oxfam International, 2007).

4. 'Climate Change: impacts, vulnerability and adaptation in developing countries', United Nations Framework Convention on Climate Change (2007) 5.

5. Ibid. 29.

6. Ravi Srinivas, another contributor to this collection, describes them as environmentally sound technologies (ESTs). See R. Srinivas, 'Climate change, technology transfer and intellectual property rights', RIS-DP \# 153, Research and Innovation System for Developing Countries (2009) 2.

7. See A. Brown et al., Towards a Holistic Approach to Technology and Climate Change: What Would Form Part of an Answer?, University of Edinburgh Working Paper Series 2010/32 (2010), available at http://papers.ssrn.com/sol3/papers. cfm?abstract_id= 1697608 . 
8. F. Hegel, The Philosophy of History (M. Sibree (trans.), Batoche Books, Ontario, 2001) 19.

9. World Bank, n. 1 above at 26.

10. Ibid. 25 .

11. For an interesting discussion of the question of access to medicines, see S. Picciotto, 'The WTO as a node of global governance: economic regulation and human rights discourses' (2007) Law, Social Justice and Global Development J 1.

12. This position has mainly been canvassed by the G77, China and other Third World countries at the UNFCCC session in Bonn, 2009.

13. Article 27 of the Universal Declaration of Human Rights (UDHR) is often used to make human rights arguments for patents. It provides that "everyone has the right to the protection of the moral and material interests resulting from any scientific, literary or artistic production of which he is the author'. A further case is made under Art. 15 of the International Covenant for Economic, Social and Cultural Rights (ICESCR), which requires the provisions under Art. 27 of the UDHR mentioned above to be balanced against the right of everyone to 'enjoy benefits of scientific progress and its applications'. The problem is not really the existence of these provisions, but rather how they are captured by corporate innovators, as opposed to real flesh and blood innovators. What this means is that there is no better time than the present to clarify who the subject of human rights ought to be. It is perhaps because of problems of this nature that a lot of scepticism exists over human rights today. These issues are considered by Brown in Chapter 8.

14. P. Drahos, with J. Braithwaite, Information Feudalism: Who Owns the Knowledge Economy (Routledge, London, 2002) 7.

15. I wish to thank Elisa Walker for pointing out to me that the only permanent measure that can lead to the suspension of an IPR relates to anti-competitive measures.

16. Trade-Related Aspects of Intellectual Property Rights (TRIPS) Agreement, Annex 1C, Marrakesh Agreement establishing the World Trade Organization (1994).

17. International Centre for Trade and Sustainable Development, Climate Change, Technology Transfer and Intellectual Property Rights (2008) 2.

18. F. Schauer, 'Commensurability and its constitutional consequences' (1994) 45 Hastings LJ 791.

19. Schauer cites Ronald Dworkin's seminal idea of 'rights as trumps' as a good example of this position.

20. Schauer, n. 18 above, 787.

21. See M. Nussbaum, Creating Capabilities: The Human Development Approach (Harvard University Press, Cambridge, MA, 2011) 51.

22. See M. Sandel, Public Philosophy: Essays on Morality in Politics (Harvard University Press, Cambridge, MA, 2006) 149.

23. C. Cannady, 'Access to climate change technology by developing countries: a practical strategy' (2009) 25 International Centre for Trade and Sustainable Development 2.

24. M. Khor and S. Shashikant, 'Intellectual property and technology transfer issues in the context of climate change' (2010) 14 Intellectual Property Rights Series, Third World Network 3.

25. Ibid. 15 .

26. The floods in Pakistan in 2010 illustrate this point. The appalling response from the Pakistan government to the floods provoked a great deal of anger from citizens and observers across the globe. This is not just something that has happened in Pakistan, as parallels can be drawn with the US government's response to Hurricane Katrina. The events relating to Hurricane Katrina illustrate that the neglect of communities can take place even in one of the most powerful countries of the world. 
27. The fact that there are hardly any public-public partnerships through which communities can build coalitions and also learn from each other is telling.

28. TRIPS, n. 16 above.

29. The fair trade movement, which deals directly which farmers or farm families, is one good example of what I am talking about. There are others, from social enterprise to cooperative societies, which can provide a framework to deal directly with marginalized communities. Mohammed Yunus' work on micro-credit institutions or social business could be a model in this respect. It shows how social businesses, which operate in a different kind of market, can be designed specifically for the vulnerable and poor. See M. Yunus, Banker to the Poor: Micro-Lending and the Battle against World Poverty (Public Affairs, Jackson, TN, 1999).

30. J. Ife, Human Rights from Below: Achieving Rights Through Community Development (Cambridge University Press, Cambridge, 2010) 2-3.

31. C. Douzinas, The End of Human Rights (Hart Publishing, Oxford, 2000) 274.

32. D. Schlosberg, 'Reconceiving environmental justice: global movements and political theories' (2004) 13 Environmental Politics 517.

33. See I. Young, Justice and the Politics of Difference (Princeton University Press, Princeton, 1998). See also I. Young, Inclusion and Democracy (Oxford University Press, Oxford, 2000).

34. N. Fraser, 'Social justice in the age of identity politics: redistribution, recognition and participation' in 19 Tanner Lecturers on Human Values (Utah University Press, Utah, 1998); N. Fraser, 'Rethinking recognition' (2000) 3 New Left Review 120. On Fraser's work, see T. Lovell, 'Nancy Fraser's integrated theory of justice: a sociologically rich model for a global capitalist era?' (2007) Law, Social Justice and Global Development $J 1$.

35. Schlosberg, n. 32 above.

36. Ibid.

37. Douzinas, n. 31 above.

38. A. Honneth, The Struggle for Recognition: The Moral Grammar of Social Conflicts (MIT Press, Cambridge, 1995); A. Honneth, 'Recognition or redistribution? Changing perspectives on the moral order of society' (2001) 18(2-3) Theory, Culture and Society 43.

39. Douzinas, n. 31 above, at 276.

40. See A. Williams, 'Human rights and law: between sufferance and insufferability' (2006) Law Quarterly Review 123 at 132-57.

41. See M. Robinson and S. Humphreys, Human Rights and Climate Change (Cambridge University Press, Cambridge, 2009).

42. Ibid. 1 .

43. Ibid. iii.

44. Ibid.

45. See A. Sen, The Idea of Justice (Penguin Books, Harlow, 2009); see also A. Sen, 'Elements of a theory of human rights' (2004) 32(4) Philosophy and Public Affairs 315.

46. Ibid.

47. Declaration on the Right to Development adopted 4 December 1986, GA Res. 41/128. UN GAOR, 41st Sess., at 3, Annex, UN Doc. A/Res/41/128 Annex (1987). On the right to development, see A. Sengupta, 'On the theory and practice of the right to development' (2002) 24 Human Rights Quarterly 837.

48. E. Petersmann, 'Theories of justice, human rights and the constitution of international markets', 17 EUI Law Working Paper (2003).

49. See F. Garcia, 'The global market and human rights: trading away the human rights principle' (1999) 25 Brooklyn J International Law 1. 